\title{
Schizosaccharomyces pombe U4 Small Nuclear RNA Closely Resembles Vertebrate U4 and is Required for Growth
}

\author{
Thomas Dandekar $\dagger$, Véronique Ribes $\dagger$ and David Tollervey $\dagger$
}

\author{
Génie Microbiologique, Institut Pasteur \\ 75724 Paris Cedex 15, France
}

(Received 23 February 1989)

\begin{abstract}
The single-copy gene snu4, which encodes the small nuclear RNA (snRNA) U4, has been cloned and sequenced. Schizosaccharomyces pombe U4 is 128 nucleotides in length, similar in size to vertebrate $\mathrm{U} 4$ and shows substantial primary and secondary structure homology. The gene lacks sequences closely resembling vertebrate snRNA transcription signals, but has a TATA box at -33 to -30 ; TATA sequences flanked by several additional conserved nucleotides are found in the same position in the $5^{\prime}$ regions of other snRNA genes from Schiz. pombe.

The cloned snu4 gene was disrupted by transposon mutagenesis and used to replace one

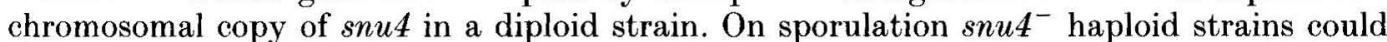
not be recovered, demonstrating that $\mathrm{U} 4$ is required, at least for spore germination. Haploid $s n u 4^{-}$strains are viable if they also carry $s n u 4^{+}$on a replicating plasmid but are unable to loose the plasmid under non-selective growth, demonstrating a continuous requirement for $\mathrm{U} 4$ for viability.
\end{abstract}

\section{Introduction}

The small nuclear RNAs (snRNAsł) are a group of stable low molecular weight RNA species found in the nuclei of all eukaryotes examined to date, which are believed to play roles in a variety of RNA processing reactions. The most studied species, designated $\mathrm{U} 1, \mathrm{U} 2, \mathrm{U} 4, \mathrm{U} 5$ and $\mathrm{U} 6$, are all required for pre-messenger RNA (pre-mRNA) splicing in vitro (for a review, see Maniatis \& Reed, 1987). Splicing of pre-mRNA occurs within a complex structure termed a spliceosome. Major events in spliceosome assembly include the association of U1 and U2 small nuclear ribonucleoproteins ( $\mathrm{snRNPs}$ ) with the $5^{\prime}$ splice junction and site of branch formation, respectively. U4 and $\mathrm{U} 6$ snRNA are associated by hydrogen-bonding and are found in a single snRNP particle (Bringmann et al., 1984; Hashimoto \& Steitz, 1984) and may associate with the spliceosome as a U4/U5/U6 complex; U4 is released from the spliceosome before intron cleavage (Pikielny et al., 1986; Cheng \& Abelson, 1987; Lamond et al., 1988). The site and mechanism of action of U4 snRNP remains obscure but it is essential for splicing activity in vitro. We wished

$\uparrow$ Present address: European Molecular Biology Laboratory, Meyerhofstrasse 1, 6900 Heidelberg, F.R.G.

\$ Abbreviations used: snRNAs, small nuclear RNAs; snRNPs, small nuclear ribonucleoproteins; bp, basepairs; $\mathrm{kb}, 10^{3}$ bases or base-pairs. therefore to use molecular genetic techniques to study the function of U4 snRNPs in vivo.

Genetic analyses in the budding yeast Saccharomyces cerevisiae (S.cerevisiae) have shown that the major spliceosome-associated snRNAs, including $\mathrm{U} 4$, are all essential for viability (Siliciano et al., 1987; for a review, see Guthrie \& Patterson, 1988). However, it is clear that, while many features are common between pre-mRNA splicing in S. cerevisiae and higher eukaryotes, there are also distinctive differences in the system of $S$. cerevisiae. We therefore considered it to be useful to analyse genetically the role of snRNPs in the fission yeast Schizosaccharomyces pombe (Schiz. pombe), in which both the RNA and protein components of the snRNPs as well as signals in pre-mRNA introns, are rather closer to those of higher eukaryotes (Tollervey \& Mattaj, 1987; Käufer et al., 1985; Brennwald et al., 1988; D. Tollervey, G. Tessars \& R. Lührmann, unpublished results).

We have previously reported the identification of snRNAs from Schiz. pombe including the analogues of vertebrate U1-U6 and the cloning of the genes encoding several such snRNAs, including the singlecopy gene snu4 (Tollervey \& Mattaj, 1987; Tollervey, 1987; Dandekar \& Tollervey, 1989).

Schiz. pombe $\mathrm{U} 4$ is similar in size to vertebrate $\mathrm{U} 4$ and has many features characteristic of snRNAs: (1) it is localized in the nucleus; (2) it carries the distinctive 2,2,7-trimethylguanosine cap structure 
unique to snRNAs; (3) it is in a ribonucleoprotein particle, associated with proteins that are immunologically related to the vertebrate "Sm-proteins" common to U1, 2, 4 and 5 ; and (4) it retains a conserved, functional binding site for such proteins since Schiz. pombe U4 is able to associate with Xenopus Sm-proteins following microinjection into Xenopus oocytes.

Since, both the RNA and protein components of Schiz. pombe U4 snRNPs appear to have been highly conserved with respect to those of vertebrates, it is likely to be of value in analysing the function of this snRNP in vivo. As a first step in such an analysis, we have determined whether $\mathrm{U} 4$ is required for viability.

\section{Materials and Methods}

(a) Strains and media

Growth and handling of Schiz. pombe have been described by Gutz et al. (1974). The diploid strain used for gene disruption carries $h^{+}, \quad$ leu1.32/ $h^{+}$, leu1.32, ura4-D18/ura ${ }^{-}$D18; ade 6.704/ade 6.704 (P. Nurse, personal communication).

\section{(b) Chromosomal DNA}

DNA was prepared by a modification of the technique of Holm et al. (1986). Crude nuclei fractionated as described by Dandekar \& Tollervey (1989) were used to prepare chromosomal DNA. Nuclei were resuspended in $2.2 \mathrm{ml}$ of $100 \mathrm{~mm}-\mathrm{NaCl}, \quad 20 \mathrm{~mm}-$ Tris-HCl $\quad(\mathrm{pH} 8)$, $50 \mathrm{~mm}-\mathrm{EI}$ TA. To this was added $0.24 \mathrm{ml}$ of $20^{\circ} \% \mathrm{~N}$ lauryl sarcosyl and $10 \mathrm{mg}$ of proteinase $\mathrm{K}$, and the tubes were incubated at $37^{\circ} \mathrm{C}$ for $1 \mathrm{~h}$. The lysate was cleared by centrifugation in an Eppendorf centrifuge and the supernatant was loaded onto $7.5 \mathrm{ml}$ of saturated $\mathrm{CsCl}_{2}$ in TE buffer ( $10 \mathrm{~mm}$-Tris $(\mathrm{pH} 8), 1 \mathrm{~mm}-\mathrm{EDT}$ T) and centrifuged in an SW4l rotor. Fractions containing chromosomal INA, identified by their high viscosity, were prooled and dialysed against TE buffer.

\section{(c) Sequence analysis}

'The sequence analysis was carried out using the assistance of the GCY software package (Devereux ol al., 1984). The alignments for the primary structure were obtained using the program "gap" of the above package for the pairwise comparisons to Schiz. pombe (gap weight 50 , gap length weight 0.3 ) before the sequences were aligned together and the common alignment was further optimized.

\section{(d) $R N A$}

RNA was prepared by the hot phenol/guanidinium method (Maniatis et al.. 1982) as modified by Tollervey \& Mattaj (1987). Immunoprecipitations of RNA were carried out as described by Tollervey \& Mattaj (1987). The U4 RNA 3 ' sequence was determined enzymically (Donis-Keller et al.. 1977) using gel-purified immunoprecipitated RNA. The 5 ' RNA sequence was determined by primer extension as described by Geliebter (1987), using an oligonucleotide complementary to nucleotides 56 to 72 of Schiz. pombe U4.

\section{(e) DNA sequencing}

The sequence of the snu4 gene was determined by dideoxynucleotide chain termination (Sanger et al., 1977). The region shown was sequenced on both strands.

\section{(f) Transposon mutagenesis and transformation}

The method of transposon mutagenesis was as described by Seifert et al. (1986). The transposon inserted, m-Tn3 (LEU2), carries the S. cerevisiae selective marker LEU2, which complements the leu1- mutation of Schiz. pombe (Beach \& Nurse, 1981). Schiz. pombe was transformed using the protocol described for $S$. cerevisiae by Ito et al. (1983).

\section{Results}

\section{(a) Localization and sequence of snu4}

The cloning of the gene snu4 and several other snRNA genes from Schiz. pombe has been reported (Dandekar \& Tollervey, 1989). Southern hybridization using probe prepared from purified U4 was used to localize the gene to and within the $940 \mathrm{bp}$ genomic HindIII-EcoRI fragment shown in Figure 1. This region was sequenced using dideoxy nucleotides. The $3^{\prime}$ end of the coding region was identified by comparison with the $3^{\prime}$ end RNA sequence obtained from purified U4 snRNA. The $5^{\prime}$ end of the coding region was identified by primer extension with an oligonucleotide complementary to nucleotides 56 to 72 of the RNA. These gave a single $3^{\prime}$ and a single $5^{\prime}$ end-point at the positions indicated. The length of the RNA given by these end-points is very close to our estimates of the size of $\mathrm{U} 4$ based on gel mobility. However, the slight possibility that the RNA might be a few nucleotides longer and that the stop in the primer extension reaction might be due to reasons other than the true end of the RNA cannot be completely exciuded. The 128-nucleotide RNA sequence and the DNA sequence extending to 208 nucleotides $5^{\prime}$ and 463 nucleotides $3^{\prime}$ of the coding region are shown in Figure 2.

No sequences with high homology to the consensus vertebrate snRNA gene transcription signals were detected. However, a TATA sequence (underlined in Fig. 2 ) is present at -33 to -30 ), a position similar to that of TATA sequences of other genes of Schiz, pombe transcribed by polymerase II (Russel, 1983). The snu4 gene carried by YKpsnu4 has only 220 nucleotides of $\boldsymbol{5}^{\prime}$ flanking sequence. Northern hybridization shows that this is sufficient for full expression of the snu4 gene (data not shown). Comparison of the $3^{\prime}$ flanking region of snu4 with those of snuz (T. Dandekar \& I). Tollervey, unpublished results; J. A. Wise, personal communication) and snu $3 \mathrm{~A}$ (Porter ot al., 1988) reveals a region of moderate sequence conservation (underlined in Fig. 2) at a position similar to that of the transcription termination signals of vertebrate $\mathrm{U}$ snRNA genes (for a review, see I)ahlberg \& Lund, 1988). 


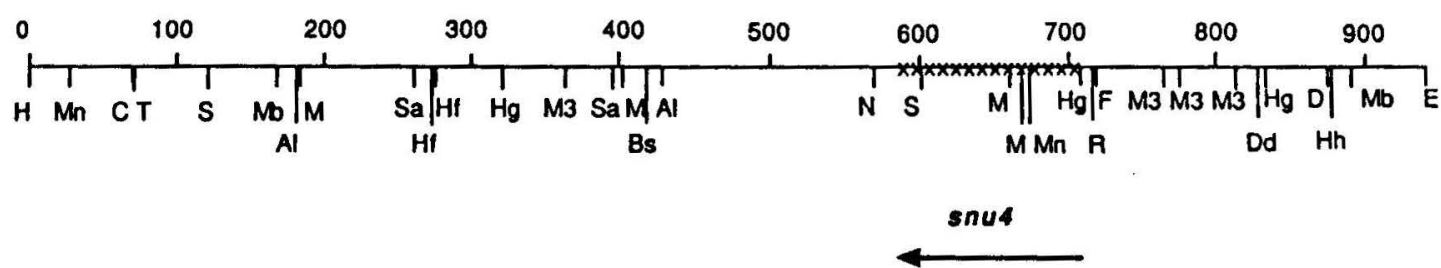

Figure 1. Restriction map of snu4. The restriction map of the region surrounding the genomic snu4 locus is shown. C, ClaI; D, DraI; Dd, DdeI; Al, AluI; Bs, BsmI; E, EcoRI; F, FokI; H, HindIII; Hf, HinfI; Hg, HgiaI; Hh, HhaI; M, MaeI; M3, MaeIII; Mb, MboII; Mn, MnlI; S, SspI; Sa, SauIIIa; T, TaqI; N, NdeI; R, RsaI. The snu4 coding region is hatched and an arrow indicates the direction of transcription.

\section{(b) U4 structure}

Comparison of the primary structure of $\mathrm{U} 4$ from Schiz. pombe and a number of other eukaryotes is shown in Figure 3. These RNAs are clearly homologous. The number of matched nucleotides is 77 for human, 72 for rat, 81 for chicken, 79 for Drosophila, 73 for bean and 82 for S. cerevisiae.

Figure 4 shows a comparison of a proposed secondary structure for human U4 (Rinke et al.,
1985) and a possible secondary structure for Schiz. pombe U4. Blocks of identical nucleotides are enclosed in boxes, and a potential Sm-binding site (AGUUUUGG) is drawn in bold type. Another sequence with homology to a consensus Sm-binding site (AAUAUUUGG) is present at positions 112 to 120 (underlined in Fig. 4), and in fact this sequence is aligned against the Sm-binding sites of other organisms in Figure 3. This sequence, however, has an A residue within the poly(U) tract, in contrast to

-200
ATACATACCTATACATATÁTCAGTTTTGCAAATCTTCCCCTTTGCGCTTTAAAACTCTCA

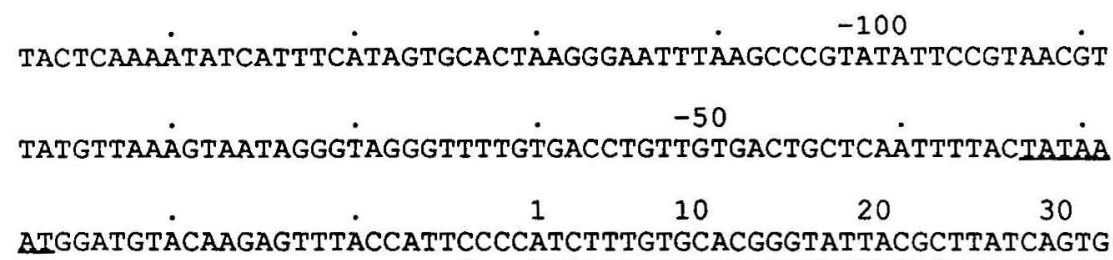

GpPpAUCUUUGUGCACGGGUAUUACGCUUAUCAGUG

$\begin{array}{llllll}40 & 50 & 60 & 70 & 80 & 90\end{array}$

AGGAACTTTTCCTAGATGGCGTTATTGCTAGTTGAAAACTATTACCCTGACCGCTCCAAC AGGAACUUUUCCUAGAUGGCGUUAUUGCUAGUUGAAAACUAUUACCCUGACCGCUCCAAC $\begin{array}{cccc}100 & 110 & 120 & 128 \\ \text { TCTCGTTAAGAGTTTGGGAATATTGGAAACCAACTTATTGCAATAACTCATATGTTTA }\end{array}$ UCUCGUUAAGAGUUUUGGGAAUAUUUGGAAACCAAC $\mathrm{OH}$

CAATGTATGTCTTTAGCAATTTGGTGGTTTTTATTTTTTGTAAAATTAATTTTATATGA

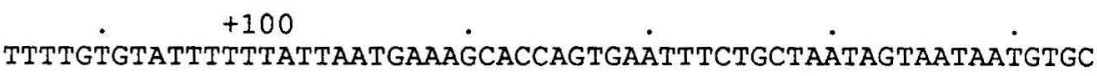
+150 . 0 . $\quad$. +200 TTACCGAAATAAGGAǴCTAAAAGCATTCAGTAATCTTTTGCTAGGCAGAGATCAAGATAA CGTAAATTTTGTTATÁTAATATGTTÁCGCTTTCCTTGTTTTATAGACCTGTTAGCCATTA

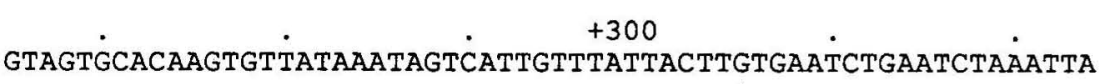

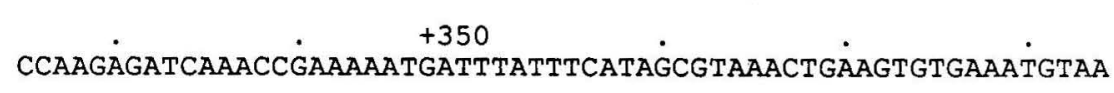
$\stackrel{+400}{\text { AGTCGGGTATGATAAATATATCTAGCTTTCTGTTGAAGAGAACACATTAAAAGTATTATA }}$
$+450 \quad$ ATGGATAAAAGAGAGAAT

Figure 2. Sequence of snu4. The sequence of the snu4 coding region is shown together with the flanking regions, extending to 208 nucleotides $5^{\prime}$ and 463 nucleotides $3^{\prime}$ of the coding region. The inferred RNA sequence is also shown together with its $5^{\prime}$ eap structure. A TATA-like sequence and a potential termination signal are underlined. 
Sp. : AUCUUUGUGCACGgGUAUUACGC . UUAUCAGUGAGgAACUUUUCCUAGAUंGgCGUU Hs . : AGCUUUGCGCAGUGGCAGUAUCG. UAGCCAAUGAGG . UUUAUCCGAGGCGCGAUU

Rn . : GAACUUU. . GCAGUGGCAGUAUCG . UAGCCAAUGAGG. . UUUAUCCGAGGCGCGAUU

Gg . : . AGCUUUGCGCAGUGGCAGUAUCG. UAGCCAAUGAGG . . UUUAUCCGAGGCGCGAUU Dm. : . AGCUUAGCGCAGUGGCAAUACCG. UAACCAAUGAAG. . CCUCCCUGAGGUGCGGUU Vf . : . AUCUUUGCGCUUGGGGCAAUGACGUAGCUAGUGAGGU. UCUAACCGAGGCGCGUCU Sc . : . AUCCUUAUGCACGGGAAAUACGCA. UAUCAGUGAGGA. UUCGUCCGAGAUUGUGUU

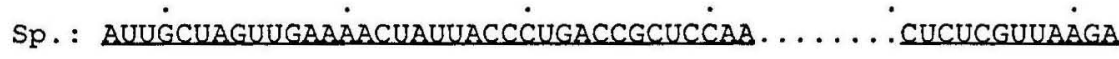

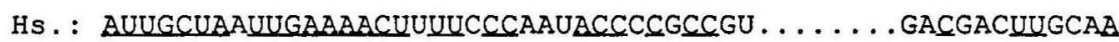

Rn.: AUUGCUAAUUGAAAACUUUUCCCAAUACCCCGCCGU....... GACGACUUGAAA

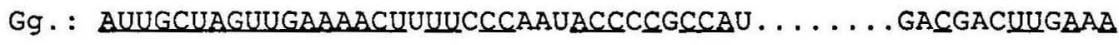

Dm. : AuUgCUAGUUGAAAACU. UUAACCAACCCACGCCAU....... GgGACGUGAAAU

Vf . : AUUGCUGGUUGAAAACUAUUUGCCAAACCCCUCUUAGGCUUGGGCUUGGGUUCAAG

Sc. : UUUGCUGGUUGAAAUUUAAUUAUAAACCAGACCGUC. . . . . . UCCUCAUGGUCA

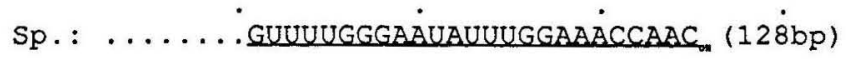

$$
\begin{aligned}
& \text { Hs.: UAUAGUCGGCAUUGGCAAUUUUUGACAGUCUCUACGGAGACUGG }
\end{aligned}
$$

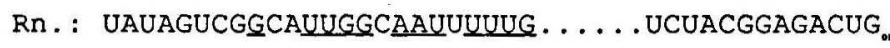

$$
\begin{aligned}
& \text { Gg . : UAUAGUCGGCAUUGGCAAUUUUUGAGAGCCUCCCCGGAG } \\
& \text { Dm. : ACCGUCC. ACUACGGCAAUUUUUGGAAGCCCUUACGAGGGCUAA }
\end{aligned}
$$

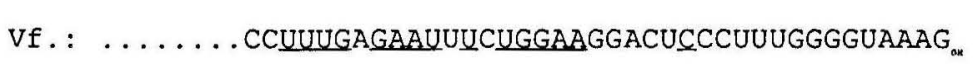

$$
\begin{aligned}
& \text { Sc. : AUUCGUG *AUGUAGGGAAUUUUUGGAAUACCUUUон } \\
& \text { (* = UUCGCUUUGAAUACUUCAAGACCU) }
\end{aligned}
$$

Figure 3. Alignment of nucleotide sequences of U4 RNAs. The primary sequence of Schiz. pombe U4 was aligned with U4 snRNAs from a range of other eukaryotes using the computer program of Devereux et al. (1984). Organisms are: Sp, Schiz. pombe; Hs., Homo sapiens; Rn., Rattus norvegicus; Gg., Gallus gallus (chicken); Dm., Drosophila melanogaster Vf., Vicia faba (broad bean); Sc., S. cerevisiae. A region of 24 nucleotides (shown in parentheses) was omitted from the $S$. cerevisiae sequence at the site marked by an asterisk in order to allow the Sm-binding site of $S$. cerevisiae to be aligned with other Sm-binding sites.

Sm-binding sites from other snRNAs (Reddy, 1988) including Schiz. pombe U2 (Brennwald et al., 1988). If the sequence at nucleotides 112 to 120 is indeed the Sm-binding site, then the predicted secondary structure would more closely resemble that of $S$. cerevisiae, with stem/loop III extended and stem/loop IV absent. An alternative secondary structure for U4, proposed by Myslinski et al. (1984) on the basis of comparison with the Drosophila U4 sequence, is modified from that shown in Figure 4 by an extension of stem 1 and reduction of loop II. The structure derived is not compatible with the sequence of Schiz. pombe U4.
The loop II region is highly conserved from human to Schiz. pombe U4. To determine whether this region is also conserved in U4 snRNAs from other fungi an oligonucleotide complementary to nucleotides 56-72 of Schiz. pombe U4 was synthesized. This oligonucleotide hybridizes strongly to U4-sized RNAs from Aspergillus nidulans, Neurospora crassa, Candida albicans, Saccharomyces diastaticus and S. cerevisiae (data not shown).

Phylogenetic comparisons have led to the proposition of the "Y"-model for the structure of the U4/U6 interaction (Brow \& Guthrie, 1988). The sequence of Schiz. pombe $\mathrm{U} 6$ has been reported 

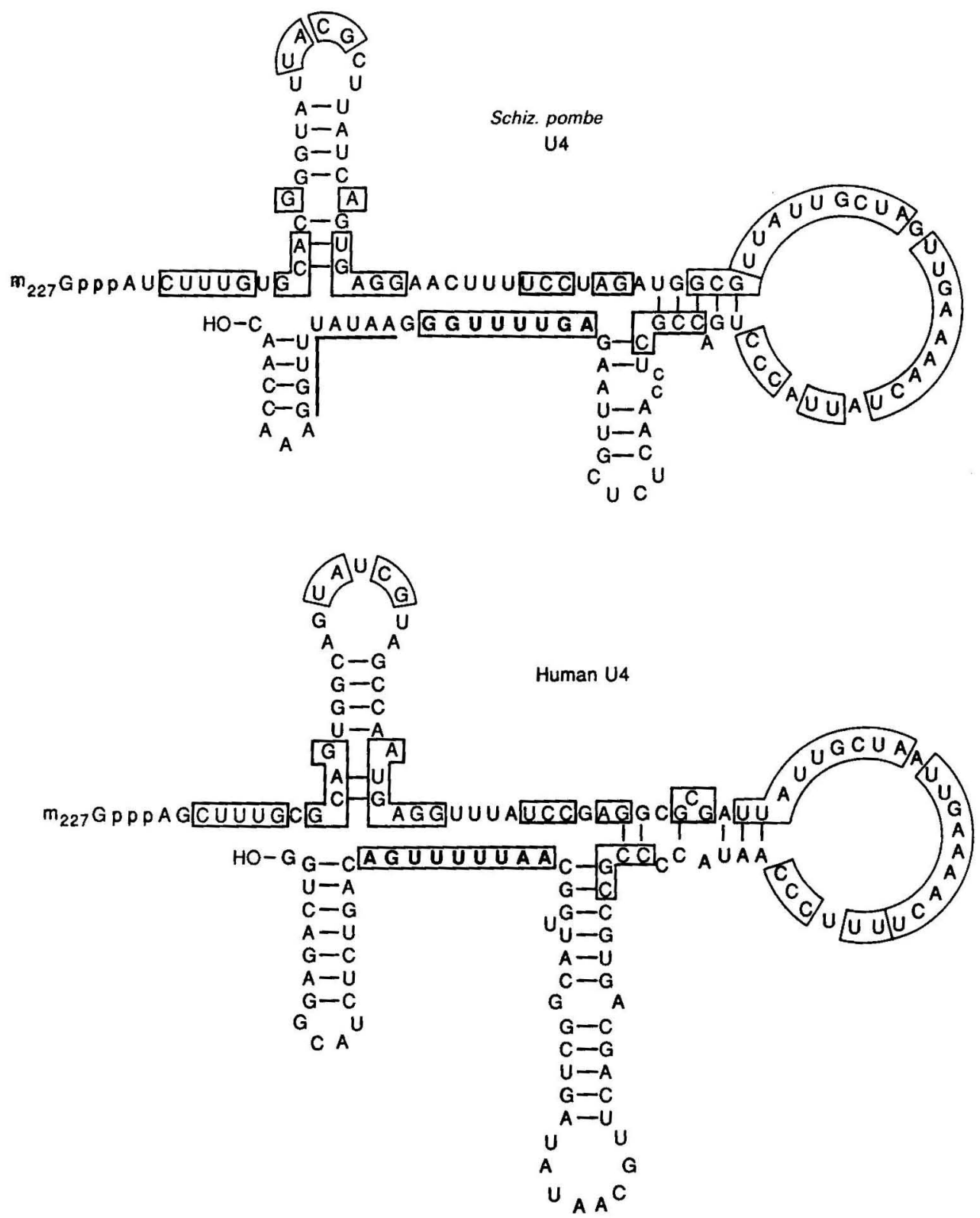

Figure 4. Comparison of predicted secondary structures of Schiz. pombe and human U4. Human U4 is drawn according to the secondary structure of Rinke et al. (1985). Schiz. pombe U4 is drawn to resemble this structure. Boxed regions contain identical sequences. The putative Sm-binding site is shown in bold type and a second sequence with homology to the Sm-binding site is underlined (see the text).

('Tani \& Ohshima, 1989). U4 and U6 from Schiz. pombe can be drawn in a Y-structure closely resembling that of human U4/U6 (Fig. 5) with a stable stem formed between nucleotides 19 to 28 and 47 to 56 of Schiz. pombe U4 giving a loop exactly the size of that in human U4. The proposed Schiz. pombe Y structure also gives stable stems between nucleotides 1 and 16 of $\mathrm{U} 4$ and 53 and 68 of U6 and nucleotides 58 and 65 of $\mathrm{U} 4$ and nucleotides 43 and 50 of U6.

\section{(c) Disruption of snu4}

The gene snu4 has been shown to be present in a single copy in haploid cells (Dandekar \& Tollervey,
1989). To determine whether this gene is required for viability, a gene replacement experiment was performed. Cloned snu4 was disrupted by insertion of a Tn3 transposon carrying $\mathrm{AMP}^{\mathrm{R}}$ and the $L E U 2$ gene from S.cerevisiae. Plasmids in which the transposon is inserted into the coding region were identified by Southern hybridization with eDNA probe prepared from purified U4. The disrupted copy of snu4 was used to replace one chromosomal copy of snu4 in a diploid strain homozygous for leu1.32, which is complemented by the LEU2 gene carried by the transposon (Beach \& Nurse, 1981; Seifert et al., 1986; Ribes et al., 1988). Of four transformed diploids analysed by genomic Southern blots, three gave the pattern of bands predicted for 

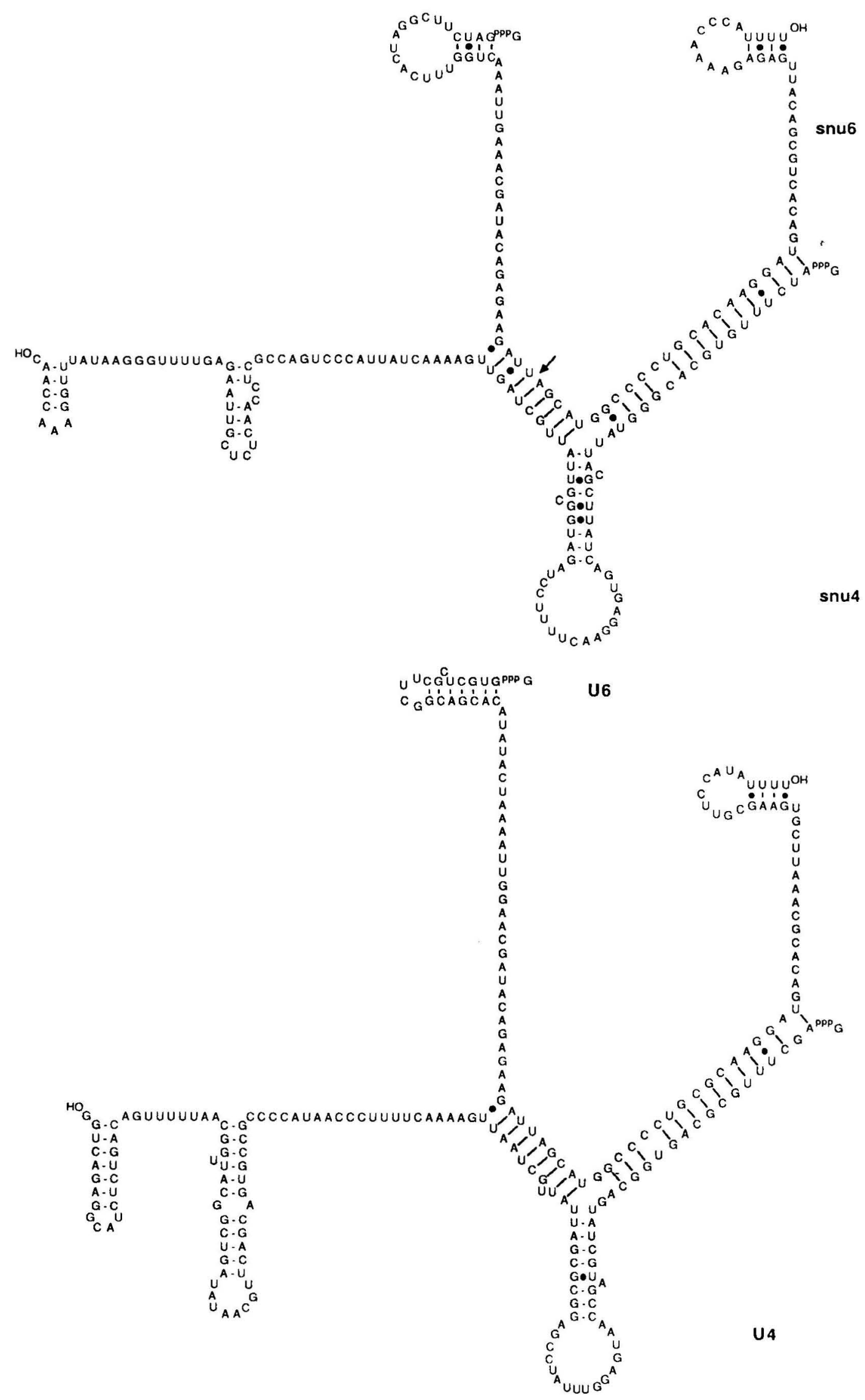

Figure 5. Proposed interaction of U4 and U6. Schiz. pombe U4 and U6 (upper panel) and human U4 and U6 (lower panel) are drawn in the Y-structure proposed by Brow \& Guthrie (1988). The site of the intron in Schiz. pombe U6 (Tani \& Ohshima, 1989) is indicated by an arrow. Two potential stem/loop structures, conserved in position between both U6 sequences are drawn at the $5^{\prime}$ and $3^{\prime}$ ends of human and Schiz. pombe U6. The positions of Watson-Crick base-pairs (-) and $\mathrm{G} \cdot \mathrm{U}$ base-pairs $(\mathcal{O})$ are indicated. 


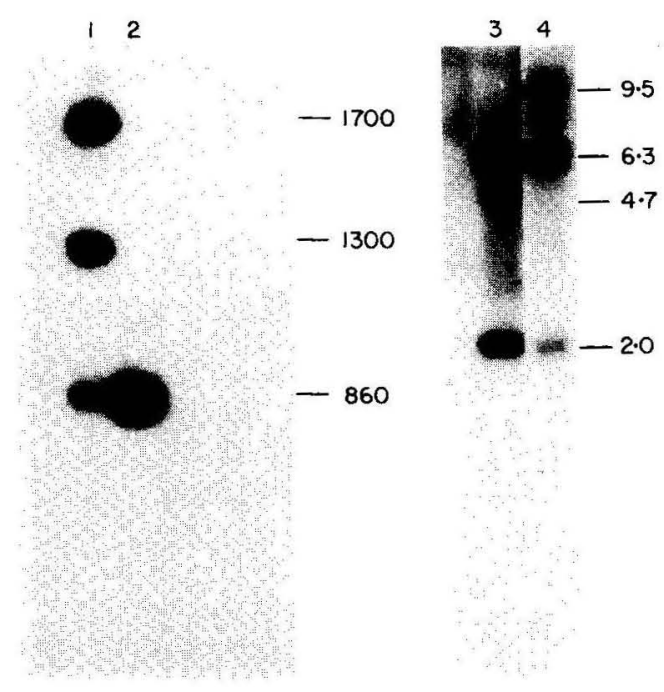

Figure 6. Southern analysis of strains carrying the $s n u 4$ gene disruption and a complementing plasmid. Lane 1, diploid heterozygous for snu4:Tn3(LEU2)/snu4 $4^{+}$; lane 2, wild-type diploid; lane 3, diploid heterozygous for snu4 :: $\operatorname{Tn} 3(L E U 2) / s n u 4^{+}$; lane 4 , haploid strain carrying snu4:: $\operatorname{Tn} 3(L E U 2)$ and the complementing plasmid YEpsnu4. Chromosomal DNA from each strain was digested with EcoRI and ClaI (lanes 1 and 2) or HindIII (lanes 3 and 4). Estimated sizes of the bands are indicated in nucleotides on the left and $\mathrm{kb}$ on the right. The hybridization probe was prepared from a fragment of DNA extending from the $5^{\prime}$ end of the snu4 gene to the $S s p$ I site within the coding region (Fig. 1).

correct gene replacement at the snu4 locus (Fig. 6). Digestion with EcoRI and ClaI gives a $\mathbf{8 6 0}$ nucleotide genomic DNA fragment (Fig. 1), which is visible in Figure 6 , lanes 1 and 2 . In the transformed diploid (Fig. 6, lane 1) additional bands of 1.3 and $1.7 \mathrm{~kb}$ are expected, due to cleavage at the EcoRI sites within the transposon (Seifert et al., 1986). The hybridization probe is to a region entirely within the coding sequence of snu4, demonstrating that this region has indeed been interrupted by the insertion. 'The growth of the diploid carrying one disrupted copy of snut is indistinguishable from that of the wild-type parent. 1)ensitometer tracing of Northern hybridizations demonstrate that the ratio of $\mathrm{U} 2 / \mathrm{U} 4$ in these strains is identical, indicating that the regulation of snut is such as to provide complete dosage compensation.

The transformed diploid is homozygous $\mathrm{h}^{+} / \mathrm{h}^{+}$at the mating-type locus. To obtain haploid spores, rare $\mathrm{h}^{90} / \mathrm{h}^{+}$revertants were identified (Gutz et al., 1974), which switch mating type to $\mathrm{h}^{-} / \mathrm{h}^{+}$and sporulate. Amongst 2700 haploid spores, none was found to carry the inserted $L E U^{+}$marker, demonstrating that snu4 is essential, at least for spore germination.

\section{(d) Genetic complementation with snu4}

To determine whether snu4 is also required for vegetative growth, and to confirm fully that the

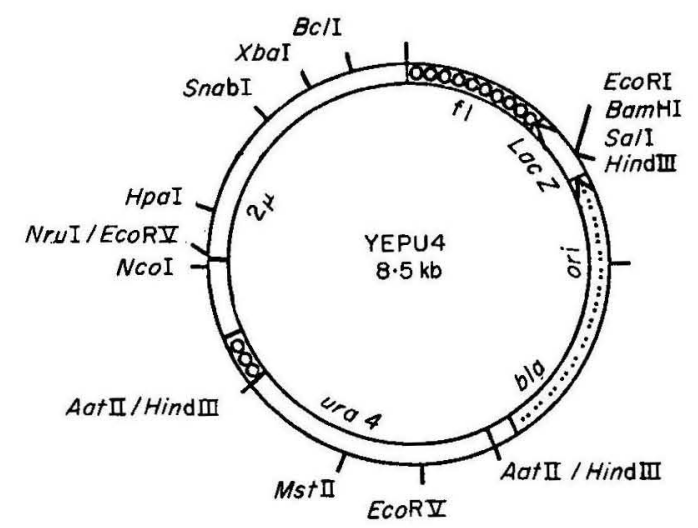

Figure 7. Plasmid YEpU4. The plasmid was constructed by deletion of the $N r u \mathrm{I}-E c o \mathrm{RV}$ fragment carrying the $U R A 3$ gene from the plasmid pEMBLYe23 (Cesareni \& Murray, 1987) and insertion of a $1.8 \mathrm{~kb}$ HindIII fragment carrying the ura 4 gene of Schiz. pombe as a blunt-ended fragment at the single AatII site. Unique restriction sites predicted from the sequences are shown. Restriction digests confirm that all sites shown are present on the plasmid. In Escherichia coli the plasmid confers ampicillin resistance, contains the lac $Z$ complementing fragment, which permits blue/white colour testing for insertions and carries the Fl replication origin, enabling the single-stranded form of the plasmid to be isolated (orientation as for transcription of lac $Z$ ) by co-infection and packaging by phage $\mathrm{F} 1$. The $1.8 \mathrm{~kb}$ ura 4 fragment inserted in YEpU4 corresponds to the region precisely deleted in ura4-D18 strains (Grimm et al., 1988) and the plasmid therefore has no regions of homology to genomic DNA in such strains.

lack of $\mathrm{U} 4$ is responsible for the lack of growth of the $\mathrm{LEU}^{+}$haploids, a complementation experiment was performed.

A Schiz. pombe replicating plasmid, YEpU4, has been constructed (Fig. 7) that carries the S. cerevisiae $2 \mu$ origin of replication and the ura4 gene from Schiz. pombe, together with the phage Fl replication origin, which permits the isolation of single-stranded DNA molecules suitable for IDA sequencing or in vitro mutagenesis. The $940 \mathrm{bp}$ ÉcoRI-HindIII region containing snut (Fig. 1) was subcloned into YEpU4 to generate YEpsnu4. The sequence of the snut fragment is not compatible with it containing an intact protein gene, and this region does not hybridize to other small RNA species. The snu4:: Tn3(LEU2)/snu $4^{+}$diploids also carry ura4-D18/ura4-D18 (Grimm et al., 1988), and YEpsnu4 was transformed into such a strain. Spores from the diploid carrying YEpsnu4 were plated on medium lacking uracil to select for those that had retained the plasmid during meiosis, and replicated onto medium with and without leucine. Of 90 spores tested, $53 \%$ carried the inserted LEU2 marker. Southern hybridization of two separate $\mathrm{LEU}^{+}$strains confirmed that they lack an intact genomic copy of snu4 (Fig. 6). The transformed diploid (Fig. 6, lane 3) and the snu4- haploid (Fig. 6, lane 4) give rise to HindIII fragments of $2 \cdot 0$ and $6 \cdot 3 \mathrm{~kb}$, due to the disruption of the $4.7 \mathrm{~kb}$ 
genomic HindIII fragment carrying snu4 by the transposon $(3 \cdot 6 \mathrm{~kb})$ which contains a single HindIII site (Seifert et al., 1986). In the diploid strain (lane 3), but not in the haploid strain (lane 4), there is an intact chromosomal copy of the snu4 gene, which gives rise to the $4.7 \mathrm{~kb}$ genomic HindIII fragment. In the haploid strain (lane 4) the $9.5 \mathrm{~kb}$ band is the complementing YEpsnu4 plasmid, which carries the intact snu4 allele, linearized by cleavage at the unique HindIII site (Fig. 7). The

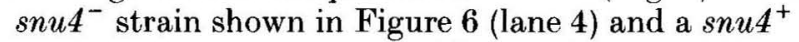
sister strain were grown without selection for the YEpsnu4 plasmid for approximately 12 generations. Cells from each culture were plated on non-selective medium and replicated onto media with and without uracil, to test for the presence of the plasmid. From 900 snu4 $4^{+}$colonies, $150(17 \%)$ were found to retain the plasmid, a value in good agreement with our previous estimates of the stability of this plasmid. From $900 \mathrm{snu4^{- }}$ colonies, $100 \%$ retained the YEpsnu4 plasmid. The same result was obtained in three independent experiments.

\section{Discussion}

U4 snRNA from Schiz. pombe shows high primary sequence homology to U4 snRNAs from vertebrates, insects, plants and the budding yeast S.cerevisiae. Perhaps surprisingly, overall homology of Schiz. pombe U4 compared with any of the other species is similar, with generally around 60 to $63 \%$ matched nucleotides. U4 from Schiz. pombe can be drawn in secondary structure very similar to the structure of "free" U4 (i.e. not associated with U6) proposed by Rinke et al. (1985). In addition, Schiz. pombe U4 and U6 can be drawn in a $\mathrm{Y}$ structure as proposed for the U4/U6 interaction (Brow \& Guthrie, 1988), which also very closely resembles that of human U4/U6.

In current models for spliceosome function, the active enzymic components are RNA molecules, the snRNAs and the pre-mRNA. The high evolutionary conservation of U6 and the release (or less-tight association) of U4 from the spliceosome prior to intron cleavage (Pikielny et al., 1986; Cheng \& Abelson, 1987; Lamond et al., 1988) has led to the further suggestion that $\mathrm{U} 6$ is the enzymically active component, and that the role of U4 is to act as a carrier for $\mathrm{U} 6$ and to block its activity until the appropriate moment. However, it is notable that only a part of the region of highest primary sequence conservation between U4 from Schiz. pombe and vertebrates corresponds to the U4/U6 interaction domain. The very high evolutionary conservation of the whole of the loop II region of U4 strongly suggests that U4 plays some more active role in spliceosome function.

Following microinjection into Xenopus oocytes, Schiz. pombe U4 becomes associated with Xenopus snRNP proteins that are stockpiled in the cytoplasm (Zeller et al., 1983; Tollervey \& Mattaj, 1987). This demonstrates that Schiz. pombe U4 retains a functional "Sm-binding site": a short nucleotide sequence, which is apparently sufficient to permit the association of RNA species with the "Sm-proteins" that are common between U1, 2, 4 and 5 (Branlant et al., 1982; Mattaj \& De Robertis, 1985). A sequence (AGUUUUGG) similar to a consensus Sm-binding site is found in a singlestranded region of Schiz. pombe U4.

Neither the Xenopus U2 nor S.cerevisiae U5 genes are detectably expressed in Schiz. pombe (D. Tollervey, unpublished results). Consistent with this, we detect no sequences with good homology to the vertebrate snRNA gene consensus distal sequence element (DSE), which acts as an enhancer, or to the proximal sequence element (PSE), which fulfils the role of a TATA box. Genes encoding snRNAs from $S$. cerevisiae also lack sequences homologous to PSE and DSE elements, but have well-conserved TATA sequences located between -80 and -100 (for a compilation of such sequences, see Bally et al., 1988), a position similar to that of TATA boxes for several other genes transcribed by RNA polymerase II in S. cerevisiae. The Schiz. pombe snu4 gene does not have a TATA box in this region but does have a TATA sequence at -33 to -30 , a position similar to that of TATA sequences of other polymerase II genes from Schiz. pombe (Russel, 1983). It is striking that a TATA sequence is found in identical positions in the Schiz. pombe snu2 gene (D. Tollervey \& T. Dandekar, unpublished results; J.A. Wise, personal communication) and, at a similar position in the snu 3 A gene (Porter et al., 1988); several additional nucleotides around the TATA box are also conserved between these genes, lending increased significance to the conservation of this region. Comparison of six genes encoding U2 from a plant, Arabidopsis, reveals that these too have a conserved TATA sequence, surrounded by a number of other completely conserved nucleotides, situated at a distance from the initiation site identical with that of the Schiz. pombe TATA sequences (Vankan \& Filipowicz, 1988).

As the first step in our genetic analysis of the function of U4 in vivo, we have demonstrated that it is essential for viability. The failure to recover snu $4^{-}$haploids from a diploid carrying only one intact copy of the snu4 gene demonstrates that the snu4 gene is at least required for spore viability or germination. Haploid snu4 ${ }^{-}$strains can be recovered if they also carry an intact copy of snu4 on a replicating plasmid, demonstrating that the failure of snu4 $4^{-}$strains to grow is due to a lack of U4 snRNA. These strains are unable to lose the complementing plasmid over many generations of unselected growth, demonstrating that $\mathrm{U} 4$ is continuously required for vegetative growth. These experiments also provide the genetic proof that snu4 is the only gene encoding U4 in Schiz. pombe and that the gene-disruption experiments have indeed resulted in replacement at the snu 4 locus.

The techniques used here should be of general use in analysing the structure and function of genes in 
Schiz. pombe. The transposon mutagenesis system, developed for $S$. cerevisiae (Seifert et al., 1986) enables essentially random insertions to be made in any gene, even if the sequence is not known. This is particularly useful for making insertions into snRNA genes, which, owing to their small size, frequently lack convenient restriction sites. The plasmid we have constructed permits the complementation of the disrupted gene in haploid cells. Since it carries the phage Fl replication origin, this plasmid can be used directly to construct and sequence in vitro mutations for complementation testing.

We thank Jörg Kohli and Kinsey Maundrell for providing the cloned ura4 gene and sequence, and Paul Russel and Paul Nurse for providing the strain used for the gene disruption experiment. T.D. was supported by the Deutsche Forschungsgemeinschaft.

\section{References}

Bally, M., Hughes, J. \& Cesareni, G. (1988). Nucl. Acids Res. 16, 5291-5303.

Beach, D. H. \& Nurse, P. M. (1981). Nature (London), 290, 140-142.

Branlant, C., Krol, A., Ebel, J. P., Lazar, E., Haendler, B. \& Jacob, M. (1982). EMBO J. 1, 1259-1262.

Brennwald, P., Porter, G. \& Wise, J.-A. (1988). Mol. Cell. Biol. 8, 5575-5580.

Bringmann, P., Appel, B., Rinke, J., Reuter, R., Theissen, H. \& Lührmann, R. (1984). EMBO J. 3, 1357-1363.

Brow, D. \& Guthrie, C. (1988). Nature (London), 334, 213-218.

Cesareni, G. \& Murray, J. A. H. (1987). In Genetic Engineering (Setlow, J. K., ed.), vol. 9, pp. 135-154, Plenum Publ. Corp., New York.

Cheng, S.-C. \& Abelson, J. (1987). Genes Develop. 1, 10141027.

Dahlberg, J. E. \& Lund, E. (1988). In Small Nuclear Ribonucleoprotein Particles (Birnstiel, M. L., ed.), Springer-Verlag, Berlin and Heidelberg.

Dandekar, T. \& Tollervey, D. (1989). Gene, in the press.

Devereux, J., Haeberli, P. \& Smithies, O. (1984). Nucl. Acids Res. 12, 387-395.

Donis-Keller, H., Maxam, A. M. \& Gilbert, W. (1977). Nucl. Acids Res. 4, 2527-2538.

Geliebter, J. (1987). Focus, 9, 5-8.
Grimm, C., Kohli, J., Murray, J. \& Maundrell, K. (1988). Mol. Gen. Genet. 215, 81-86.

Guthrie, C. \& Patterson, B. (1988). Annu. Rev. Genet., 22, $387-419$.

Gutz, H., Heslot, H., Leupold, U. \& Loprieno, N. (1974). In Handbook of Genetics (King, R. C., ed.), vol. 1, pp. 395-446, Plenum Press, New York.

Hashimoto, C. \& Steitz, J. A. (1984). Nucl. Acids Res. 12, $3283-3293$.

Holm, C., Meeks-Wagner, D. W., Fangman, W. L. \& Botstein, D. (1986). Gene, 42, 169-173.

Ito, H., Fukuda, Y., Murata, K. \& Kimura, A. (1983). J. Bacteriol. 153, 163-168.

Käufer, N. F., Simanis, V. \& Nurse, P. (1985). Nature (London), 318, 78-80.

Lamond, A. I., Konarska, M. M., Grabowski, P. J. \& Sharp, P. A. (1988). Proc. Nat. Acad. Sci., U.S.A. 85, 411-415.

Maniatis, T. \& Reed, R. (1987). Nature (London), 325 673-678.

Maniatis, T., Fritsch, E. F. \& Sambrook, J. (1982). Editors of Molecular Cloning: A Laboratory Manual, Cold Spring Harbor Laboratory Press, Cold Spring Harbor, NY.

Mattaj, J. W. \& De Robertis, E. M. (1985). Cell, 40, 111118

Myslinski, E., Branlant, C., Wieben, E. D. \& Pederson, T. (1984). J. Mol. Biol. 180, 927-945.

Pikielny, C. W., Rymond, B. C. \& Rosbash, M. (1986). Nature (London), 324, 341-345.

Porter, G. L., Brennwald, P. J., Holm, K. A. \& Wise, J. A. (1988). Nucl. Acids Res. 16, 10131-10152.

Reddy, R. (1988). Nucl. Acids Res. 16 (Suppl.), r71-r85.

Ribes, V., Dehoux, P. \& Tollervey, D. (1988). EMBO J. 7, 231-237.

Rinke, J., Appel, B., Digweed, M. \& Lührmann, R. (1985). J. Mol. Biol. 185, 721-731.

Russel, P. (1983). Nature (London), 301, 167-169.

Sanger, F., Nicklen, S. \& Coulson, A. R. (1977). Proc. Nat. Acad. Sci., U.S.A. 74, 5463-5467.

Seifert, H. S., Chen, E. Y., So, M. \& Heffron, F. (1986). Proc. Nat. Acad. Sci., U.S.A. 83, 735-739.

Siliciano, P. G., Brow, D. A., Roiha, H. \& Guthrie, C. (1987). Cell, 50, 585-592.

Tani, T. \& Ohshima, Y. (1989). Nature (London), 337, $87-90$.

Tollervey, D. (1987). J. Mol. Biol. 196, 355-361.

Tollervey, D. \& Mattaj, I. W. (1987). EMBO J. 6, 469 476.

Vankan, P. \& Filipowicz, W. (1988). EMBO J. 7, 791 799

Zeller, R., Nyffenegger, T. \& De Robertis, E. M. (1983). Cell, 32, 425-434. 